\title{
Recurrent N209* ABHD5 mutation in two unreported families with Chanarin Dorfman Syndrome
}

\author{
Daniela Tavian (1,2), Murat Durdu (3), Corrado Angelini (4), Enza Torre (1,2), Sara \\ Missaglia (1,2) \\ (1) Laboratory of Cellular Biochemistry and Molecular Biology, CRIBENS, Università Cattolica \\ del Sacro Cuore, Milan, Italy; (2) Department of Psychology, Università Cattolica del Sacro \\ Cuore, Milan, Italy; (3) Baskent University Faculty of Medicine, Department of Dermatology, \\ Adana Hospital, Adana, Turkey; (4) Neuromuscular Laboratory, Department of Neurosciences, \\ University of Padova, Campus Biomedico Pietro d'Abano, Padua, Italy \\ This article is distributed under the terms of the Creative Commons Attribution Noncommercial License (CC BY-NC 4.0) which permits \\ any noncommercial use, distribution, and reproduction in any medium, provided the original author(s) and source are credited.
}

\begin{abstract}
ABHD5 protein is widely involved in lipid and energy homeostasis. Mutations in the ABHD5 gene are associated with the onset of Neutral Lipid Storage Disease with Ichthyosis (NLSDI), historically known as Chanarin Dorfman Syndrome (CDS). CDS is a rare autosomal recessive lipid storage disease, characterized by non-bullous congenital ichthyosiform eritrhoderma (NCIE), hepatomegaly and liver steatosis. Myopathy, neurosensory hearing loss, cataracts, nystagmus, strabismus, and mental impairment are considered additional findings. To date, 151 CDS patients have been reported all over the world. Here we described two additional families with patients affected by CDS from Turkey. Our patients were a 42 and 22-years old men, admitted to the Hospital for congenital ichthyosis. Hepatic steatosis and myopathy were also detected in both patients. ABHD5 molecular analysis revealed the presence of N209* mutation. Our data enlarge the cohort of CDS patients and provide a revision of muscle clinical findings for this rare inborn error of neutral lipid metabolism.
\end{abstract}

Key Words: Lipid metabolism defect; lipid droplets; Chanarin Dorfman syndrome; ABHD5 mutations; myopathy.

Eur J Transl Myol 31 (2): 9796, 2021 doi: 10.4081/ejtm.2021.9796

Neutral Lipid Storage Diseases (NLSDs) are a heterogeneous group of autosomal recessive disorders characterized by an increased accumulation of triacylglycerols (TAGs) in several tissues. Two forms of NLSDs are known: NLSD with ichthyosis (NLSDI), also known as Chanarin-Dorfman syndrome (CDS; MIM 275630), and NLSD with myopathy (NLSDM; MIM 610717). ${ }^{1}$ In 1974, Dorfman studied the cases of two sisters and two unrelated patients with congenital ichthyosiform erythroderma and lipid accumulations in the granulocytes. ${ }^{2}$ Nhe next year also Chanarin observed the presence of similar symptoms in a 22-years-old Asian woman. He excluded any other disease linked to lipid metabolism assuming impairment either of cytoplasmic lipase activity or of fatty acid transport into mitochondria. ${ }^{3}$ The major findings of CDS are nonbullous congenital ichthyosiform erythroderma (NCIE), hepatomegaly, and liver steatosis. ${ }^{4}$ Other variable features are muscle weakness, ataxia, neurosensory hearing loss, sub-capsular cataracts, nystagmus, strabismus and mental retardation. ${ }^{5,6}$ Patients are sometimes born as collodion babies. ${ }^{7}$ The clinical diagnosis is based on observation of Jordan's bodies, which are characteristic cytoplasmic vacuoles, ${ }^{8}$ on granulocytes, and then confirmed by genetic testing. The onset of CDS is caused by mutations in the ABHD5 gene. $^{9}$ This gene is located on chromosome 3p21, contains seven exons and codifies for the $\alpha / \beta$-hydrolase domain-containing protein 5 , a protein of the esterase, lipase and thioesterases subfamily. The human ABHD5 is a 349 amino acid-long protein, able to activate adipose triglyceride lipase (ATGL). ${ }^{10}$ So far, although 151 CDS patients have been reported all over the world, only 103 of them have undergone molecular testing. ${ }^{1,11,12}$ While most cases have been reported in the Mediterranean and Middle East regions, some cases have also been described in China, Japan, India and Brazil..,13-18 The largest number of patients (40 cases) has been described in Turkey, mainly due to the high incidence of consanguineous marriages. ${ }^{5,13,19}$ The most common mutation in the ABHD5 is the N209*, which has been 
identified in 52\% (21/40) of patients from Turkey and in $16 \%$ of all CDS patients (24/151). Here, we report the molecular and clinical characterization of two additional Turkish families with patients affected by CDS. Genetic analysis revealed the N209* mutation, confirming the diagnosis.

\section{Materials and Methods}

Dermatological, neurological, hepatic and muscle investigation were performed. Clinical data were collected following ethical principles reported in the Declaration of Helsinki. Peripheral blood smears were stained with May-Grünwald Giemsa to reveal Jordan's bodies in neutrophils using a light microscopy. Genomic DNA was extracted from blood samples, and ABHD5 coding regions and their intron/exon boundaries were examined by PCR analysis. Primer sequences and amplification protocol were previously described ${ }^{5}$. Finally, all PCR products were purified and sequenced (Eurofins Genomics, DNA sequencing service). Molecular analysis was carried out after obtaining the written, informed consents.

\section{Results and Discussion}

Patient $\mathbf{1}$ is a 42-year-old man admitted to Adana outpatient clinic for congenital ichthyosis. Due to his complaints, he only used topical moisturizers. His parents were not consanguineous, and he had 9 siblings (Figure 1a). His mother and two siblings had congenital ichthyosis. Dermatological examination of patient revealed widespread ichthyosis containing facial region, trunk, extensor and flexural regions, and scalp. Individual scale over the trunk was white, fine, translucent and semiadherent, while that on limbs and face was grey brown, larger in size, polygonal and adherent. There were no bullous lesions. Involvement of palms and soles, dental anomaly and nail dystrophy were absent.
Intracytoplasmic vacuoles (Jordan's anomaly) were detected in neutrophils on peripheral blood smear stained with May-Grünwald Giemsa (Figure 2a-b). Muscle strength, mental status and neurologic examination were normal, and the patient denied any hearing or visual problem. Liver transaminases, creatine kinase (CK) and serum triglyceride (TG) levels were elevated (alanine transaminase: $53 \mathrm{U} / \mathrm{L}$ [normal 5-35 U/L]; aspartate transaminase: $46 \mathrm{U} / \mathrm{L}$ [normal 5-17 U/L]; CK: $393 \mathrm{U} / \mathrm{L}$ [normal 22-200 U/L]; TG: $162 \mathrm{mg} / \mathrm{dL}$ [normal 35-130 $\mathrm{mg} / \mathrm{dL}])$. Abdominal ultrasonography was compatible with grade I hepatic steatosis. Finally, electromyographic (EMG) examination was compatible with myopathy. After 3 months of systemic acitretin treatment (25 $\mathrm{mg} /$ day), skin lesions of patient improved (Figure 2c-f). In agreement of what reported in other CDS patients, acitretin treatment led to a remarkable improvement in the appearance of the skin without any deleterious effect on liver function. ${ }^{20}$ Acitretin is a synthetic retinoid commonly used to treat severe skin problems, including ichthyosis. As a retinoid, it influences cellular division and differentiation of stratified structures of the epidermis. It exerts anti-inflammatory effect and decreases epidermal cell proliferation, inducing differentiation, and cornification. ${ }^{21}$

Patient 2 is a 22-year-old man admitted to Adana hospital because of suffering from congenital ichthyosis. His parents were relatives. He had two siblings, a sister and a brother, without clinical manifestations (Figure 1b). Dermatological examination showed features similar to patient 1: widespread ichthyosis involving facial region, trunk, extensor and flexural regions, and scalp. On the trunk region there were white, fine, translucent and semi-adherent scales, while on limbs and face grey brown, large, polygonal and adherent scales (Figure 3a-e). Also in this case, there were neither bullous lesions nor involvement of palms and soles and a

II

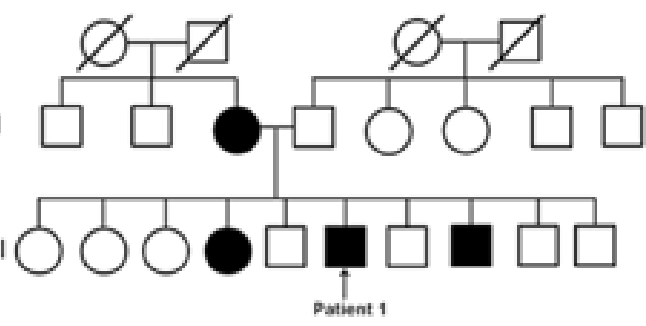

b

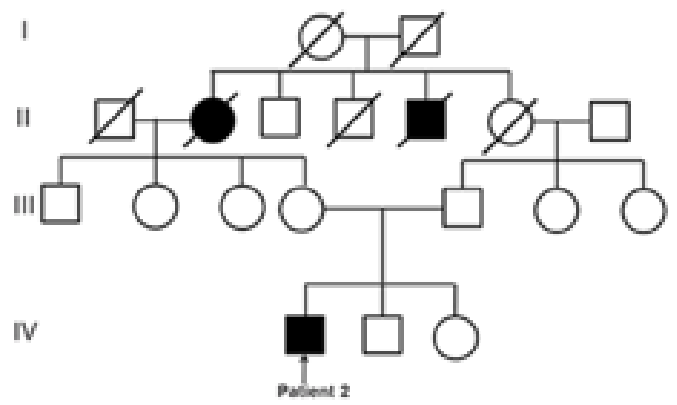

C ABHD5 gene

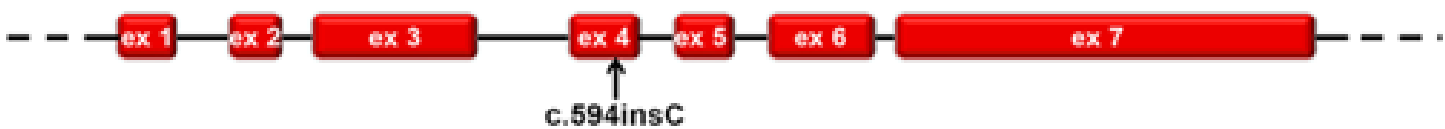

Fig 1. Characterization of two patients with CDS. Pedigree of CDS family 1 (a) and 2 (b). Localization of mutation in the ABHD5 gene identified in patient 1 and 2 (c). 


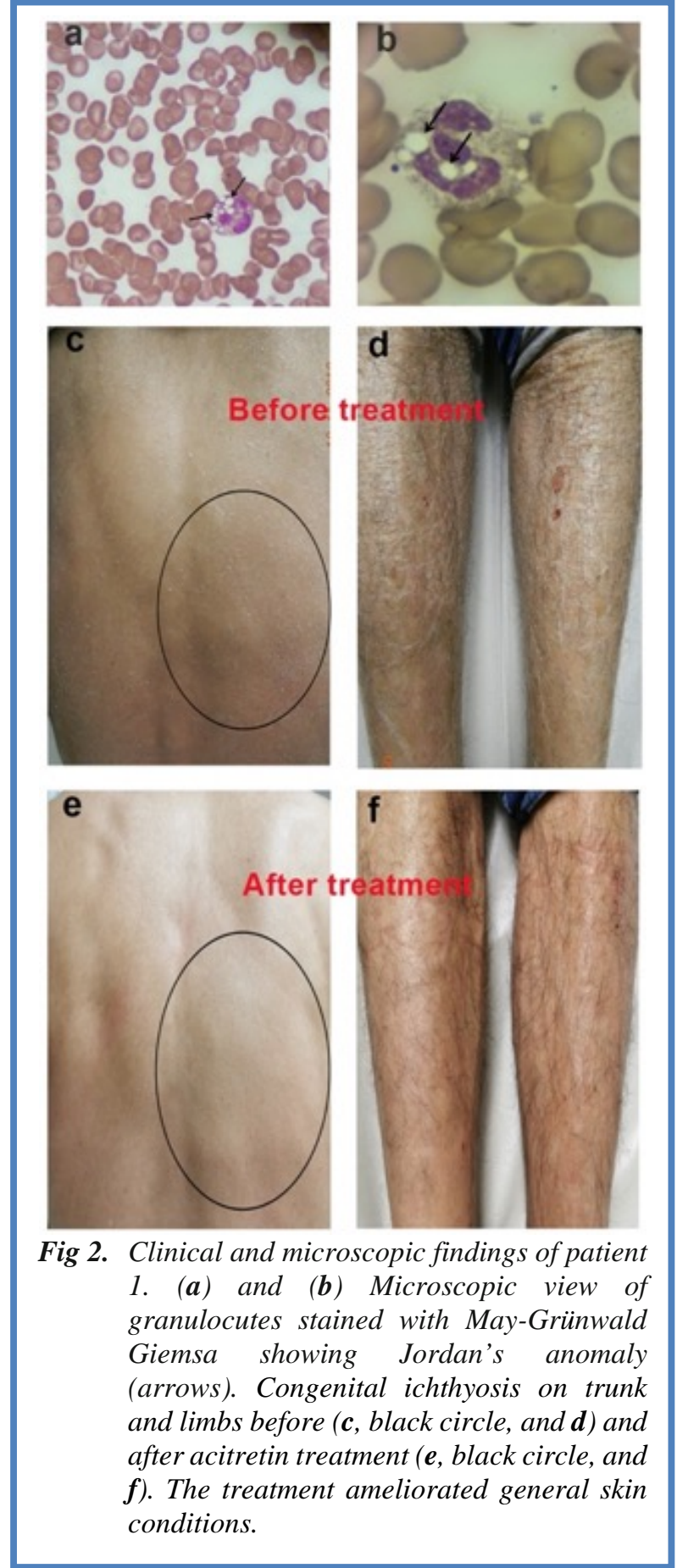

nail dystrophy. The investigation of TAG abnormal storage displayed Jordan's bodies in granulocytes (Figure 3f-h). Evaluation of muscles highlighted normal strength, while EMG examination was consistent with myopathy. Hearing or visual, as well as mental or neurologic problems were not detected. Systemic evaluation was compatible with grade I hepatic steatosis and splenomegaly (153 mm), and laboratory tests showed an increase of liver enzymes (alanine transaminase: $82 \mathrm{U} / \mathrm{L}$; aspartate transaminase: $59 \mathrm{U} / \mathrm{L}), \mathrm{CK}$ (438 U/L) and serum TGs $(178 \mathrm{mg} / \mathrm{dL})$. In the examination of the oral

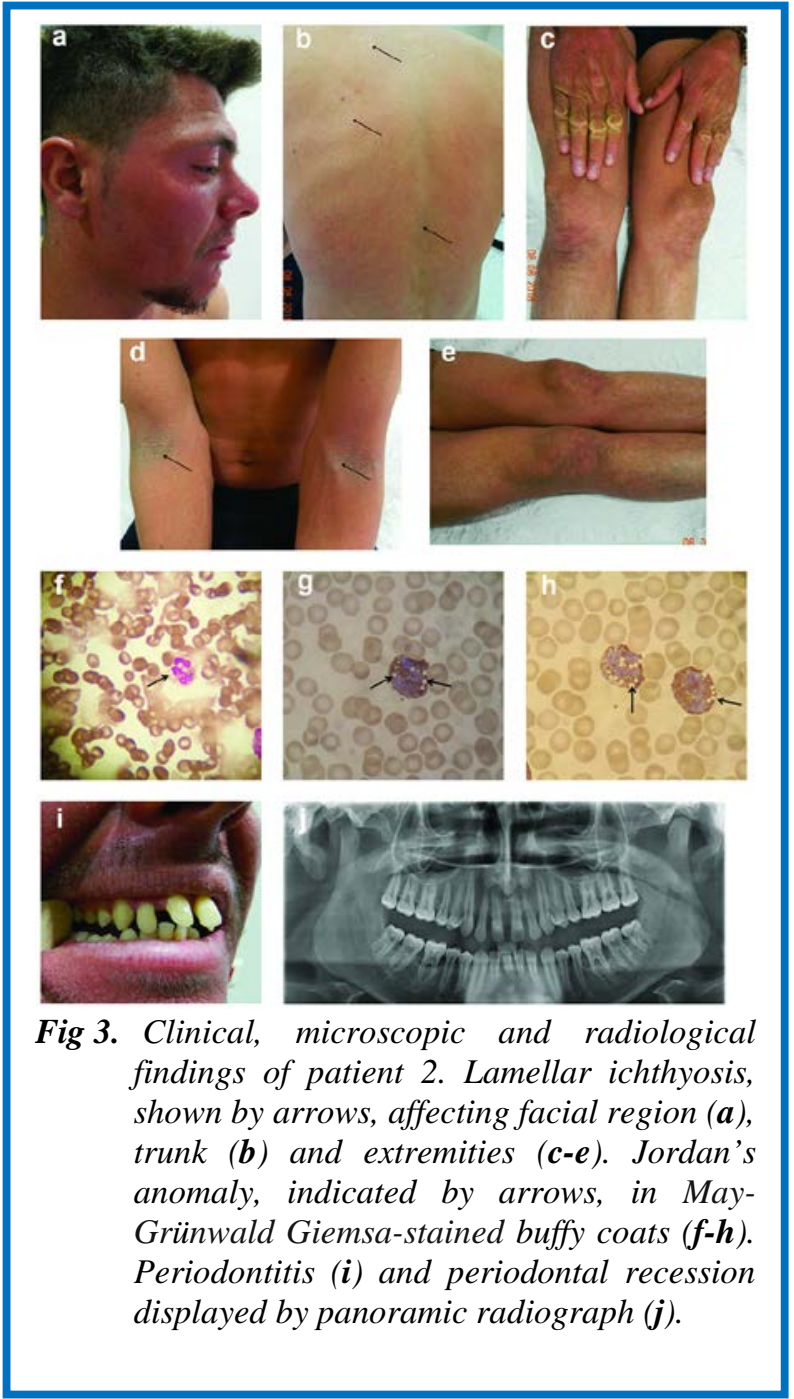

mucosa, periodontitis was detected and panoramic radiograph revealed periodontal recession (Figure 3i-j). A low triglyceride diet supplemented with MCT oil was recommended to ameliorate hepatic and skin conditions, as previously reported in many CDS patients. ${ }^{17,18,22}$ The most common ABHD5 mutation was found in our patients in homozygous state. It consists of an insertion of a cytosine in position 594 (c.594insC) (Figure 1c). The addition of this supplementary base should lead to the production of a truncated protein (p.N209*). However, it is likely that the mRNA containing the premature stop codon is going to be degraded through the nonsensemediated mRNA decay (NMD) mechanism. Indeed, thanks to NMD the cells survey mRNA quality and are able to eliminate those mRNAs carrying premature termination triplets, preventing the synthesis of truncated proteins. ${ }^{23}$ In CDS patients the lack of ABHD5 protein determines a lower efficiency of ATGL activity. ATGL catalyzes the first step in the hydrolysis of TAGs generating diacylglycerols (DAGs) and free fatty acids (FAs), stored into cytoplasmic lipid droplets (LDs). DAG is the major substrate for hormone-sensitive lipase (HSL) activity, which determines the production of FA and 


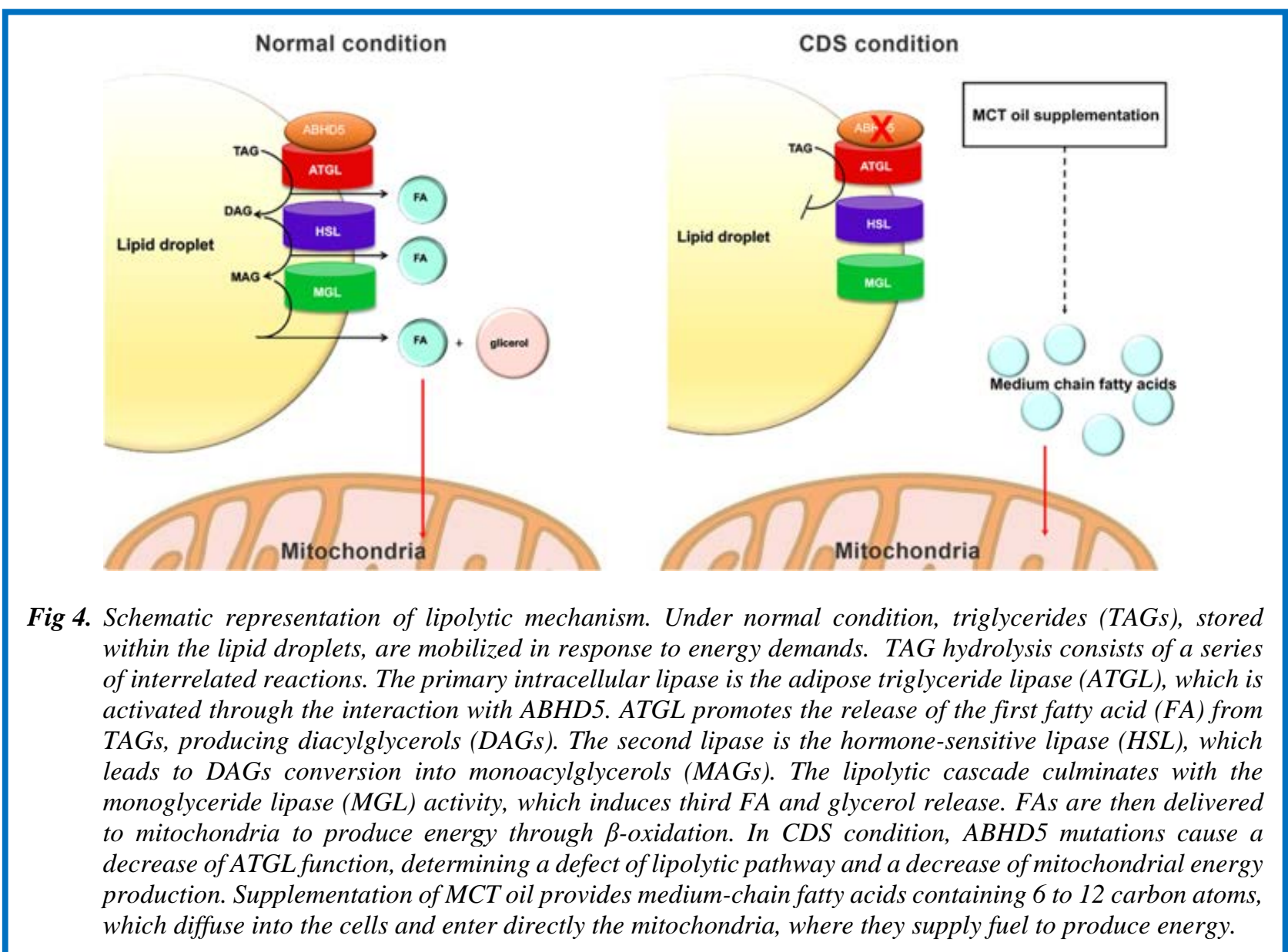

MAG (monoacylglycerol). Finally, monoglyceride lipase (MGL) catabolizes MAG to FA and glycerol. FA generated from these processes are major energy substrates for cell. ${ }^{24,25}$ In CDS patients, the biochemical pathways reported above are largely compromised, because of ABHD5 molecular defect. Consequently, a systemic increase in the size and number of LDs, and a decrease of FA availability can be detected (Figure 4). ${ }^{26}$ In many articles, a beneficial effect on CDS patients following a low triglyceride diet supplemented with MCT oil has been reported. This is probably due both to a decrease accumulation of TAGs into LDs and an increase the availability of energy by the oxidation of

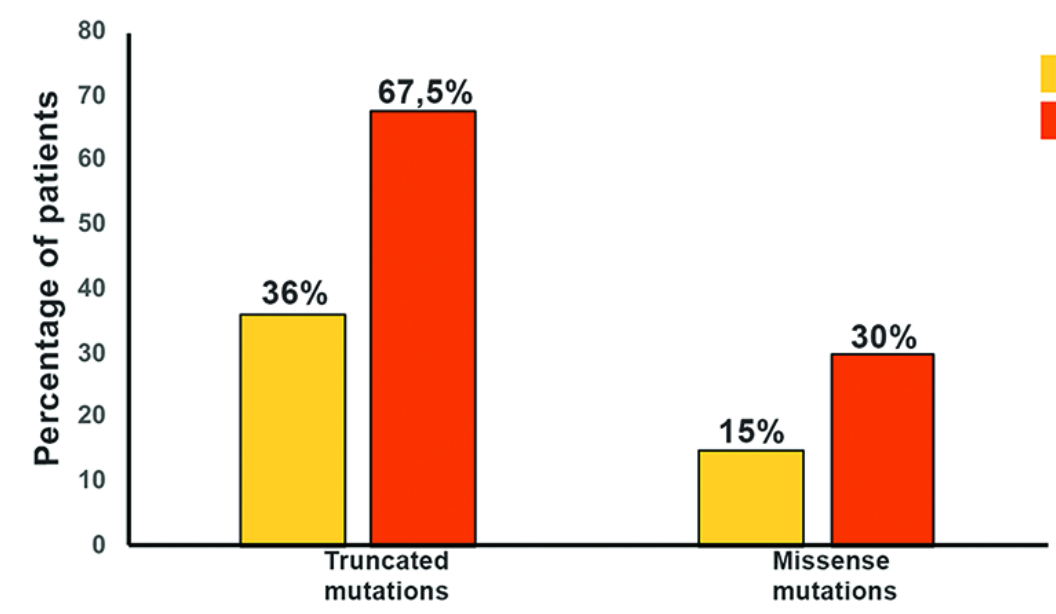

Myopathy

increase of CK levels

Fig. 5. Frequency of muscle damage in CDS patients carrying different type of ABHD5 mutations. Percentage of myopathy and CK level increase in subjects with truncated or missense ABHD5 mutations. 


\begin{tabular}{|c|c|c|c|}
\hline \multicolumn{4}{|c|}{ Table 1. Muscle involvement in CDS } \\
\hline & \multicolumn{3}{|c|}{ Patients number } \\
\hline & $0-10$ years & $11-18$ years & $>18$ years \\
\hline Country & $\begin{array}{c}\text { Italy: } 2 \\
\text { Palestine: } 1 \\
\text { Egypt: } 1 \\
\text { India: } 2 \\
\text { Turkey: } 6 \\
\text { Greece: } 1 \\
\text { Tunisia: } 1\end{array}$ & $\begin{array}{l}\text { Palestine: } 3 \\
\text { Austria: } 1 \\
\text { Turkey: } 1 \\
\text { India: } 1\end{array}$ & $\begin{array}{l}\text { Italy: } 2 \\
\text { France: } 1 \\
\text { Turkey: } 4 \\
\text { Spain: } 1 \\
\text { Tunisia: } 5\end{array}$ \\
\hline Average age & $5 \pm 2,4$ & $14 \pm 2,25$ & $36 \pm 13,6$ \\
\hline Sign of myopathy & $\begin{array}{l}\text { Hypotonia, proximal } \\
\text { muscle weakness }\end{array}$ & $\begin{array}{l}\text { Progressive } \\
\text { faticability, mild } \\
\text { myopathy, }\end{array}$ & $\begin{array}{c}\text { Proximal muscle } \\
\text { weakness, slowly } \\
\text { progressive } \\
\text { myopathy }\end{array}$ \\
\hline CK level & $\begin{array}{l}1131 \pm 642 \\
\text { (2-3 folds) }\end{array}$ & $\begin{array}{c}665 \pm 419 \\
\text { (2-3 folds) }\end{array}$ & $\begin{array}{l}683 \pm 208 \\
(2-3 \text { folds })\end{array}$ \\
\hline
\end{tabular}

CK normal range: children 68-580 UI/L; Adult 22-200 UI/L

medium chain FAs. Total or partial loss of ABHD5 function causes systemic manifestations, including ichthyosis, liver, muscle and central nervous system injury and elevation of hepatic and muscle enzymes. Ichthyosis is present in $100 \%$ of patients, while liver involvement can be detected in $85 \%$ of cases. ${ }^{1,12}$ Accordingly, our patients show NCIE, which improved only after three months of acitretin treatment. They presented also hepatic steatosis and elevated levels of liver enzymes, therefore a specific diet was recommended. Moreover, in our patients, signs of myopathy were detected by electromyography and were associated to elevated levels of CK. ABHD5 gene analysis was performed in two thirds of CDS patients (103/151). Among them, 83 subjects harbored severe mutations (causing truncated protein or no protein production), while the remaining 20 presented mild mutations (missense mutations). In the first group of patients (severe mutations, including the p.N209* mutation), signs of myopathy and elevated level of muscles enzymes (CK or CPK) were detected in 36\% and $67,5 \%$ of cases, respectively. Moreover, electromyographic study revealed early recruitment with complete interphase pattern suggestive of myopathic pattern. Instead, in the second group of patients (missense mutations), myopathy and elevated level of muscles enzymes were observed in $15 \%$ and $30 \%$ of cases, respectively (Figure 5). The evaluation of myopathy and CK levels displayed significant difference between the two groups of patients, thus indicating that total or partial impairment of ABHD5 function causes a variable muscle damage, depending from the different availability of energy. As muscles require a lot of energy to work, the partial or total impairment of ABHD5 ability to activate ATGL hinders chemical reactions involved in TAG hydrolysis, determining their build-up inside muscle cells and energy levels too low. A skeletal muscle myopathy may occur, especially in the cases of total lack of ABHD5 protein. Considering patients with myopathy, during successive decades of life (total: 33 patients), we can observe that the levels of CK and CPK increased similarly (2-3 fold) in all the intervals of times and that the myopathy, detected mainly by EMG examination, is mild or very mild in all cases and over time (Table 1). In conclusion, we described the clinical and genetic findings of two unreported CDS patients frmm different Turkish families. As CDS is an extremely rare genetic disorder and its pathophysiology is largely unknown, it is important to expand the cohort with novel patients and evaluate genotype-phenotype correlations.

\section{List of acronyms}

ABHD5- $\alpha / \beta$-hydrolase domain-containing protein 5;

ATGL - adipose triglyceride lipase;

CDS - Chanarin-Dorfman Syndrome;

CK - creatine kinase;

DAG - diacylglycerol;

EMG - electromyography;

FA - fatty acid;

HSL - hormone-sensitive lípase;

LD - lipid droplet;

MAG - monoacylglycerol; 
MGL - monoglyceride lipase

NCIE - non-bullous congenital ichthyosiform

erythroderma;

NLSDI - Neutral Lipid Storage Disease with ichthyosis;

NLSDM - Neutral Lipid Storage Disease with myopathy; NMD - nonsense-mediated mRNA decay;

TAG - triacylglycerol

\section{Authors contributions}

DT wrote and edited the manuscript; MD and CA performed clinical evaluation; ET carried out molecular analysis; SM conceived the study and supervised it. All authors read and approved the final manuscript.

\section{Acknowledgments}

The authors are grateful to the patients for their kind cooperation.

\section{Funding}

This work was supported by PRIN Grant 2017A5TXC3 (Italy)

\section{Conflict of Interest}

The authors declare they have no financial, personal, or other conflicts of interest.

\section{Ethical Publication Statement}

We confirm that we have read the Journal's position on issues involved in ethical publication and affirm that this report is consistent with those guidelines.

\section{Corresponding Author}

Sara Missaglia, Laboratory of Cellular Biochemistry and Molecular Biology, CRIBENS, Università Cattolica del Sacro Cuore, Milan, Italy.

ORCID iD: 0000-0001-6551-6698

Email: sara.missaglia@unicatt.it

\section{E-mails and ORCID iD of co-authors}

Daniela Tavian: daniela.tavian@unicatt.it ORCID iD: 0000-0003-3333-0068

Murat Durdu: sivandr@hotmail.com ORCID iD: 0000-0003-1247-3932

Corrado Angelini: corrado.angelini@unipd.it ORCID iD: 0000-0002-9554-8794

Enza Torre: enza.torre@unicatt.it ORCID iD: 0000-0001-6754-2611

\section{References}

1. Missaglia S, Coleman RA, Mordente A, Tavian D. Neutral Lipid Storage Diseases as Cellular Model to Study Lipid Droplet Function. Cells. 2019 Feb 21;8(2):187. doi: 10.3390/cells8020187.

2. Dorfman ML, Hershko C, Eisenberg S, Sagher F. Ichthyosiform dermatosis with systemic lipidosis. Arch Dermatol. 1974 Aug;110(2):261-6.

3. Chanarin I, Patel A, Slavin G, Wills EJ, Andrews TM, Stewart G. Neutral-lipid storage disease: a new disorder of lipid metabolism. Br Med J. 1975 Mar 8;1(5957):553-5. doi: 10.1136/bmj.1.5957.553..

4. Pennisi EM, Arca M, Bertini E, Bruno C, Cassandrini D, D'amico A, Garibaldi M, Gragnani F, Maggi L, Massa R, Missaglia S, Morandi L, Musumeci O, Pegoraro E, Rastelli E, Santorelli FM, Tasca E, Tavian D, Toscano A, Angelini C; Italian NLSD Group. Neutral Lipid Storage Diseases: clinical/genetic features and natural history in a large cohort of Italian patients. Orphanet J Rare Dis. 2017 May 12;12(1):90. doi: 10.1186/s13023-0170646-9.

5. Durdu M, Missaglia S, Moro L, Tavian D. Clinical and genetic characterization of a Chanarin Dorfman Syndrome patient born to diseased parents. BMC Med Genet. 2018 May 29;19(1):88. doi: 10.1186/s12881-018-0610-0.

6. Ronchetti A, Prati D, Pezzotta MG, Tavian D, Colombo R, Callea F, Colli A. Severe steatohepatitis in a patient with a rare neutral lipid storage disorder due to ABHD5 mutation. J Hepatol. 2008 Sep;49(3):474-7. doi: 10.1016/j.jhep.2008.05.027. Epub 2008 Jul 9.

7. Redaelli C, Coleman RA, Moro L, DacouVoutetakis C, Elsayed SM, Prati D, Colli A, Mela $\mathrm{D}$, Colombo R, Tavian D. Clinical and genetic characterization of Chanarin-Dorfman syndrome patients: first report of large deletions in the ABHD5 gene. Orphanet J Rare Dis. 2010 Dec 1;5:33. doi: 10.1186/1750-1172-5-33. Erratum in: Orphanet J Rare Dis. 2011 Feb 21;6(1):6.

8. Tavian D, Colombo R. Improved cytochemical method for detecting Jordans' bodies in neutral lipid storage diseases. J Clin Pathol. 2007 Aug;60(8):956-8. doi: 10.1136/jcp.2006.044917. Epub 2007 Feb 9.

9. Lefèvre C, Jobard F, Caux F, Bouadjar B, Karaduman A, Heilig R, Lakhdar H, Wollenberg A, Verret JL, Weissenbach J, Ozgüc M, Lathrop M, Prud'homme JF, Fischer J. Mutations in CGI-58, the gene encoding a new protein of the esterase/lipase/thioesterase subfamily, in ChanarinDorfman syndrome. Am J Hum Genet. 2001 Nov;69(5):1002-12. doi: 10.1086/324121. Epub 2001 Oct 2.

10. Lass A, Zimmermann R, Haemmerle G, Riederer M, Schoiswohl G, Schweiger M, Kienesberger P, Strauss JG, Gorkiewicz G, Zechner R. Adipose triglyceride lipase-mediated lipolysis of cellular fat stores is activated by CGI-58 and defective in Chanarin-Dorfman Syndrome. Cell Metab. 2006 May;3(5):309-19.

10.1016/j.cmet.2006.03.005.

11. Cakmak E, Alagozlu H, Yonem O, Ataseven $\mathrm{H}$, Citli S, Ozer H. Steatohepatitis and liver cirrhosis in Chanarin-Dorfman syndrome with a new ABDH5 mutation. Clin Res Hepatol Gastroenterol. 2012 
Apr;36(2):e34-7. doi: 10.1016/j.clinre.2011.12. 007. Epub 2012 Jan 13.

12. Louhichi N, Bahloul E, Marrakchi S, Othman HB, Triki C, Aloulou K, Trabelsi L, Mahfouth N, AyadiMnif Z, Keskes L, Fakhfakh F, Turki H. Thyroid involvement in Chanarin-Dorfman syndrome in adults in the largest series of patients carrying the same founder mutation in ABHD5 gene. Orphanet J Rare Dis. 2019 May 22;14(1):112. doi: 10.1186/s13023-019-1095-4.

13. Nur BG, Gencpinar P, Yuzbasioglu A, Emre SD, Mihci E. Chanarin-Dorfman syndrome: GenotypePhenotype Correlation. Eur J Med Genet. 2015 Apr;58(4):238-42. doi: 10.1016/j.ejmg.2015.01. 011. Epub 2015 Feb 14.

14. Ujihara M, Nakajima K, Yamamoto M, Teraishi M, Uchida Y, Akiyama M, Shimizu H, Sano S. Epidermal triglyceride levels are correlated with severity of ichthyosis in Dorfman-Chanarin syndrome. J Dermatol Sci. 2010 Feb;57(2):102-7. doi: 10.1016/j.jdermsci.2009.10.016. Epub 2009 Dec 21.

15. Takeichi T, Sugiura K, Tso S, Simpson MA, McGrath JA, Akiyama M. Bi-allelic nonsense mutations inABHD5 underlie a mild phenotype of Dorfman-Chanarin syndrome. J Dermatol Sci. 2016 Feb;81(2):134-6. doi: 10.1016/j.jdermsci.2015.10. 015. Epub 2015 Oct 27.

16. Aggarwal S, Maras JS, Alam S, Khanna R, Gupta SK, Ahuja A. Novel nonsense mutation of ABHD5 in Dorfman-Chanarin syndrome with unusual findings: a challenge for genotype-phenotype correlation. Eur J Med Genet. 2012 Mar;55(3):1737. doi: 10.1016/j.ejmg.2012.01.013. Epub 2012 Feb 6.

17. Gupta N, Gothwal S, Satpathy AK, Missaglia S, Tavian D, Das P, Timila D, Kabra M. Chanarin Dorfman syndrome: a case report with novel nonsense mutation. Gene. 2016 Jan 10;575(2 Pt 1):359-62. doi: 10.1016/j.gene.2015.09.004. Epub 2015 Sep 6.

18. Missaglia S, Valadares ER, Moro L, Faguntes ED, Quintão Roque R, Giardina B, Tavian D. Early onset of Chanarin-Dorfman syndrome with severe liver involvement in a patient with a complex rearrangement of ABHD5 promoter. BMC Med Genet. 2014 Mar 14;15:32. doi: 10.1186/14712350-15-32.

19. Eskiocak AH, Missaglia S, Moro L, Durdu M, Tavian D. A novel mutation of ABHD5 gene in a
Chanarin Dorfman patient with unusual dermatological findings. Lipids Health Dis. 2019 Dec 28;18(1):232. doi: 10.1186/s12944-019-1181-6.

20. Israeli S, Pessach Y, Sarig O, Goldberg I, Sprecher E. Beneficial effect of acitretin in ChanarinDorfman syndrome. Clin Exp Dermatol. 2012 Jan;37(1):31-3. doi: 10.1111/j.1365-2230.2011. 04164.x. Epub 2011 Oct 10.

21. Sarkar R, Chugh S, Garg VK. Acitretin in dermatology. Indian J Dermatol Venereol Leprol. 2013 Nov-Dec;79(6):759-71. doi: 10.4103/03786323.120721.

22. Srinivasaraghavan R, Krishnamurthy S, Chandar R, Cassandrini D, Mahadevan S, Bruno C, Santorelli FM. Acitretin-responsive ichthyosis in ChanarinDorfman syndrome with a novel mutation in the ABHD5/CGI-58 gene. Pediatr Dermatol. 2014 SepOct;31(5):612-4. doi: 10.1111/pde.12170. Epub 2013 Jun 12.

23. Karamyshev AL, Karamysheva ZN. Lost in Translation: Ribosome-Associated mRNA and Protein Quality Controls. Front Genet. 2018 Oct 4;9:431. doi: 10.3389/fgene.2018.00431.

24. Schweiger M, Lass A, Zimmermann R, Eichmann TO, Zechner R. Neutral lipid storage disease: genetic disorders caused by mutations in adipose triglyceride lipase/PNPLA2 or CGI-58/ABHD5. Am J Physiol Endocrinol Metab. 2009 Aug;297(2):E289-96. doi: 10.1152/ajpendo.00099. 2009. Epub 2009 Apr 28.

25. T Tavian D, Missaglia S, Redaelli C, Pennisi EM, Invernici G, Wessalowski R, Maiwald R, Arca M, Coleman RA. Contribution of novel ATGL missense mutations to the clinical phenotype of NLSD-M: a strikingly low amount of lipase activity may preserve cardiac function. Hum Mol Genet. 2012 Dec 15;21(24):5318-28. doi: 10.1093/hmg/dds388. Epub 2012 Sep 17.

26. Angelini C, Pennisi E, Missaglia S, Tavian D. Metabolic lipid muscle disorders: biomarkers and treatment. Ther Adv Neurol Disord. 2019 Apr 22;12:1756286419843359. $10.1177 / 1756286419843359$.

Submission: April 01, 2020

Revision received: April 29, 2020 Accepted for publication: April 30, 2021 